\title{
Automated Measurements of Salivary Cortisol Levels Within Circadian Rhythms Detect Differences in Exercise-induced Stress Response Between Two Altitude Training Camps
}

Katsuhiko Tsunekawa ( $\sim$ ktsune@gunma-u.ac.jp )

Gunma University Graduate School of Medicine https://orcid.org/0000-0002-6119-4158

Kazumi Ushiki

Gunma University Graduate School of Medicine

Larasati Martha

Gunma University Graduate School of Medicine

Asuka Nakazawa

Gunma University Graduate School of Medicine

Rika Hasegawa

Gunma University Graduate School of Medicine

Risa Simizu

Gunma University Graduate School of Medicine

Nozomi Shimoda

Gunma University Graduate School of Medicine

Mai Murata

Gunma University Graduate School of Medicine

Akihiro Yoshida

Gunma University Graduate School of Medicine

Kiyomi Nakajima

Gunma University Graduate School of Medicine

\section{Takao Kimura}

Gunma University Graduate School of Medicine

Masami Murakami

Gunma University Graduate School of Medicine

\section{Original Research Article}

Keywords: sequential saliva sampling, altitude training, electrochemiluminescence immunoassay (ECLIA)

Posted Date: May 25th, 2021

DOl: https://doi.org/10.21203/rs.3.rs-542158/v1 
License: (ㅇ) (1) This work is licensed under a Creative Commons Attribution 4.0 International License. Read Full License 


\section{Abstract}

Background:There are conflicting reports with regard to the superiority of cortisol as a stress marker in highaltitude training due to the influence of the circadian rhythm. This study aimed to determine if the automated measurement of salivary cortisol concentration via sequential sampling could detect the differences in acclimatization and exercise stress between two altitude camps.

Methods: A total of 12 elite female long-distance runners living near sea levels were enrolled in this study. For the first camp simulating higher altitude, the runners lived at $1800 \mathrm{~m}$ and trained at $1700 \mathrm{~m}$ for 7 days. For the second camp simulating lower altitude, they lived at $1550 \mathrm{~m}$ and trained at $1300 \mathrm{~m}$ for 7 days. Their saliva was sequentially collected on the last 2 days during each camp involving different intensity exercise in the morning and afternoon. The salivary cortisol concentrations were measured using electrochemiluminescence immunoassay.

Results: The sequential saliva collection and automated measurement were able to detect the basal levels and exercise-induced changes in the salivary cortisol within the runners' circadian rhythms in each altitude camp. Before dinner, the basal salivary cortisol concentrations were significantly higher in the higher-altitude camp. The rate of change in the salivary cortisol concentration after the afternoon exercise on day 2 of the higheraltitude camp with higher exercise intensity was significantly higher than that in the lower-altitude camp $(p=$ 0.003). The rate of change in the salivary cortisol concentration during the morning exercise on day 2 was significantly higher in the higher-altitude camp than in lower-altitude camp $(p=0.028)$ despite the same exercise programs and intensities.

Conclusions: Measurement of the salivary cortisol levels during the circadian rhythms could detect the differences in acclimatization and exercise stress between two altitude camps. Automated measurements of salivary cortisol concentrations via sequential saliva sampling may be useful for assessing adaptation disorders and excessive exercise stress and also help develop adequate high-altitude training programs for athletes.

\section{Key Points}

- Automated measurement of salivary cortisol concentration via sequential sampling could detect the circadian rhythms of the salivary cortisol in female-long distance runners and compare the basal cortisol levels in the training camps at different altitudes.

- Even in the morning easily affected by the circadian rhythm in cortisol secretion, the rate of change in salivary cortisol concentration could detect the changes in the stress response due to the exercise program of the same intensities at different altitude.

- Assessment of maladaptation and exercise-induced excessive stress in high-altitude camp through the combination of sequential saliva collection and automated cortisol measurements may contribute to the development of adequate high-altitude training programs for athletes.

\section{Background}


Elite athletes in various sports often train in high altitude environments to improve their performance once they return to sea level. At high altitudes with low atmospheric pressure and low oxygen concentration, the amount of red blood cells and their oxygen-carrying capacity are enhanced by an increase in circulating erythropoietin concentration due to hypoxia-inducible factors [1]. However, a hypoxia in high-altitude training causes excessive stress and decreases the athletes' performance, resulting in poor acclimatization [2]. Therefore, monitoring of physical and psychological stress during exercise training at high-altitude camp may help assess maladaptation.

Cortisol is an important biomarker that is secreted into the circulating plasma from the adrenal cortex via the hypothalamus-pituitary axis as an acute response to physical and psychological stress, including exercise [3]. Serum cortisol concentrations are increased by moderate- to high-intensity exercise, but not by low-intensity exercise at less than $40 \%$ of athletes' maximal oxygen consumptions $\left(\mathrm{VO}_{2}\right.$ max $)[4,5]$. The serum cortisol concentrations of healthy young men were increased by acute exercise at $40 \%$ or higher of the peak oxygen uptake $\left(\mathrm{VO}_{2 \text { peak }}\right)$ in non-athletes, but only by exercise at $90 \%$ of the $\mathrm{VO}_{2 \text { peak }}$ in well-trained endurance runners [6]. However, there are conflicting reports with regard to the superiority of cortisol as a stress marker in highaltitude training [7-12], which may be due to the influence of the circadian rhythm on cortisol. Changes in the serum cortisol concentrations by exercise are greater in the evening than in the morning due to the circadian rhythm of cortisol secretion [13]. Thus, to evaluate exercise-induced stress with cortisol, it is important to contextualize its measurements throughout the circadian rhythm. To achieve this, continuous sampling and more efficient cortisol measurement are needed. Cortisol concentrations can be measured in serum, urine, or saliva. Serum cortisol concentrations are measured as total hormone conjugated to corticosteroid-binding globulin, whereas salivary cortisol concentrations are measured as free hormones independent of salivary flow rate [14]. Saliva collection is advantageous as it can be easily performed without the stress of venipuncture in the absence of medical professional staff [15]. Recently, we reported that in female long-distance runners, sequential saliva collection and automated electrochemiluminescence immunoassay (ECLIA)-based salivary cortisol measurements could detect the exercise-induced stress within the circadian rhythm [16]. In this study, the differences in the rate of change in salivary cortisol concentrations resulting from different exercise intensities could be compared at the same time on different days, even in the early morning. We hypothesize that the measurement of salivary cortisol concentrations throughout the athletes' circadian rhythms via sequential saliva sampling enables us to assess the stress induced by high-altitude training. If proven, this method can help in the prevention of excessive stress and development of exercise programs in high-altitude environment to improve the performance of athletes. Our present study expands on our previous study by verifying whether cortisol concentration measurement via continuous saliva collection during the circadian rhythms could adequately detect the differences in acclimatization and stress response due to exercise in various altitudes in female long-distance runners.

\section{Methods}

\section{Participants}

This study was conducted in accordance to the Declaration of Helsinki, and the protocol was approved by the ethics committee of the Gunma University Graduate School of Medicine (Approval number HS2018-140). All the study participants provided written informed consent before being included in the study. 
We enrolled 12 Japanese elite female long-distance runners. All of them lived in the same dormitory before the first training camp and stayed in the same hotels during camps. Their living conditions, such as wakeup time, meal time, bedtime, and meal content, were standardized before and during the training camps [16]. Figure 1 presents the schedule and altitudes of the pre-camp and during the two training camps. The runners lived and trained near sea level $(169 \mathrm{~m})$ before the first training camp. Then, for the first training camp simulating higher altitude, they lived at $1800 \mathrm{~m}$ and trained at $1700 \mathrm{~m}$ for 7 days. Afterwards, for the second training camp simulating lower altitude, they lived at $1550 \mathrm{~m}$ and trained at $1300 \mathrm{~m}$ for 7 days then returned to near sea level. We sequentially collected salivary samples from these runners on the last 2 days during each camp involving different exercise intensities in the morning and afternoon, modified as previously described [16]. On each training day at both camps, no differences were observed in the meteorological conditions; the temperature was around $20^{\circ} \mathrm{C}$ and the humidity was $50-60 \%$ with fine weather. The runners were subjected to the following exercise program in the higher-altitude camp: 40-min fixed running in the morning and 50-min fixed running in the afternoon on day 1 (H-day 1); 8000-m fixed-distance running in the morning and uphill interval training with 8 sets of 200-m fast uphill running and light jogging in the evening on day 2 (H-day 2$)$. The runners were subjected to the following exercise program in the lower-altitude camp: 50-min fixed running in the morning and 60 -min fixed running in the afternoon on day 1 (L-day 1); 8000-m fixed-distance running in the morning and uphill interval training with 5 sets of 200-m fast uphill running and light jogging in the evening on day 2 (L-day 2). The runners drank enough water to prevent dehydration during these trainings. On both days, saliva samples were collected at eight time points: upon waking up (05:00), before morning exercise (06:00), after morning exercise (07:00), before breakfast (08:00), before lunch (12:00), before evening exercise (15:00), after evening exercise (16:00), and before dinner (18:00), as previously described [16].

\section{Physical examinations}

The participants were weighed, and the body mass index was calculated as the weight divided by the squared height $\left(\mathrm{kg} / \mathrm{m}^{2}\right)$. After interviewing them, no runners were found to take any medications or supplements. The runners used the Apple Watch Series 3 (Apple Inc. Tokyo, Japan) during the camps. This allowed for the measurement of resting pulse rate at wakeup time and before dinner, as well as the maximum pulse rate during each exercise. The distance and duration of running during each exercise session was measured, and the running velocity was calculated as the distance divided by the duration ( $\mathrm{m} / \mathrm{min}$ ) [16]. The Borg scale [17] was utilized to determine the rating of perceived exertion of the runners after exercise.

\section{Saliva collections and measurements of salivary cortisol concentrations}

Sample collections and salivary cortisol concentration measurements were performed according to a previous study [16]. The runners were not allowed to brush their teeth, chew gum, or consume any food or drink except water, 15 min before the sample collection. Saliva samples were collected using Salivette® cotton swabs (Sarstedt, Nümbrecht, Germany), centrifuged $(1,500 \times g)$ at $4^{\circ} \mathrm{C}$ for $10 \mathrm{~min}$, then immediately stored at $-80^{\circ} \mathrm{C}$ until analysis. ECLIA measurements of salivary cortisol concentrations were performed using the Elecsys Cortisol $\otimes$ on the Cobas 8000 system (Roche Diagnostics K.K, Tokyo, Japan) [16, 18]. The intra- and inter-assay coefficients of variation for salivary cortisol were $4.1 \%$ and $4.6 \%$, respectively. The rate of change in the salivary cortisol concentration by exercise was calculated as the salivary cortisol concentration after exercise divided by the salivary cortisol concentration before exercise (\%) [16]. 


\section{Statistical analysis}

The results of each measurement are expressed as the median values and corresponding 25th - 75th percentile ranges. The Wilcoxon signed-rank test was adopted to identify statistically significant differences in running distances, running velocities, Borg scale scores, maximum pulse rate, salivary cortisol concentrations, and rates of change in the salivary cortisol concentrations between two different time points. A $p$ value of $<0.05$ was considered statistically significant. All statistical analyses were performed using SPSS Statistics, version 26.0 (IBM Corp., Armonk, NY, USA).

\section{Results}

\section{Running intensity of each exercise program performed by female long-distance runners}

Table 1 presents the characteristics of female long-distance runners, whereas Table 2 presents the different running intensities of each exercise program during the two training camps. Because the exercise programs on days 1 and day 2 were similar between the two camps, the exercise intensities of each program were compared. During the morning exercise on day 1 , in higher-altitude training camp, the running velocity was significantly higher $(p=0.015)$ and the running distance and Borg scale scores were significantly lower (running distance, $p=$ 0.029 ; Borg scale score, $p=0.047$ ) than those in the lower-altitude training camp. During the afternoon exercise on day 1 , the running velocity was significantly higher in higher-altitude training camp $(p=0.003)$, but no differences were observed in other parameters between the two camps. During the morning exercise on day 2 , the maximum pulse rate was significantly lower in higher-altitude training camp $(p=0.029)$, but no differences were observed in other parameters between the two camps. However, during the afternoon exercise on day 2 , the running distance, Borg scale score, and maximum pulse rate were all significantly higher in the higher-altitude training camp (running distance, $p=0.002$; Borg scale score, $p=0.005$; maximum pulse rate, $p=0.036$ ). On day 1 , the running distance, running velocity, and Borg scale score were significantly higher during the afternoon exercise compared with those during the morning exercise in the higher-altitude camp (running distance, $p=$ 0.002 ; running velocity, $p=0.002$; Borg scale score, $p=0.010$ ), whereas the running distance was significantly higher during the afternoon exercise in the lower-altitude camp $(p=0.004)$. When comparing the exercise intensities between the morning and afternoon on day 2, the running distance and Borg scale score were significantly higher and the running velocity was significant lower during the afternoon exercise in the higheraltitude camp (running distance, $p=0.002$; Borg scale score, $p=0.004$; running velocity, $p=0.002$ ), whereas the running distance and velocity were significantly lower during the afternoon exercise in the lower-altitude camp (running distance, $p=0.002$; running velocity, $p=0.003$ ). When comparing the exercise intensities between day 1 and day 2 , the running distance in the morning $(p=0.002)$ and the running velocity in the afternoon were significantly higher $(p=0.003)$ on day 1 of the higher-altitude camp. Conversely, the running distance in the morning was significantly higher $(p=0.002)$, the maximum pulse rate in the morning was significantly lower $(p$ $=0.034$ ), and the running distance and running velocity in the afternoon were significantly higher (running distance, $p=0.002$; running velocity, $p=0.023$ ) on day 1 of the lower-altitude camp. 
Table 1

Characteristics of female long-distance runners.

\begin{tabular}{|ll|}
\hline Characteristics & Value \\
\hline Number & 12 \\
\hline Age (year) & $23.5(19.5-26.0)$ \\
\hline Height $(\mathrm{cm})$ & $160.0(155.5-164.5)$ \\
\hline Weight $(\mathrm{kg})$ & $45.5(41.0-47.5)$ \\
\hline Body mass index $\left(\mathrm{kg} / \mathrm{m}^{2}\right)$ & $17.4(17.0-17.9)$ \\
\hline Data are expressed as median (25th-75th percentile). \\
\hline
\end{tabular}


Table 2

Running intensities of the exercise programs performed by female long-distance runners during the two camps.

\begin{tabular}{|c|c|c|c|c|c|c|c|c|c|}
\hline & \multirow[t]{2}{*}{$\begin{array}{l}\text { Altitude } \\
\text { camp }\end{array}$} & \multicolumn{3}{|l|}{ day 1} & \multicolumn{3}{|l|}{ day 2} & \multicolumn{2}{|c|}{$\begin{array}{l}\text { day } 1 \text { vs. day } \\
2\end{array}$} \\
\hline & & $\begin{array}{l}\text { morning } \\
\text { exercise }\end{array}$ & $\begin{array}{l}\text { afternoon } \\
\text { exercise }\end{array}$ & $p_{\text {day } 1}$ & $\begin{array}{l}\text { morning } \\
\text { exercise }\end{array}$ & $\begin{array}{l}\text { afternoon } \\
\text { exercise }\end{array}$ & $p_{\text {day2 }}$ & $p_{m}$ & $p_{a}$ \\
\hline \multirow[t]{2}{*}{$\begin{array}{l}\text { Exercise } \\
\text { program }\end{array}$} & Higher & $\begin{array}{l}40-\text { min } \\
\text { fixed } \\
\text { running }\end{array}$ & $\begin{array}{l}50-\text { min } \\
\text { fixed } \\
\text { running }\end{array}$ & & $\begin{array}{l}8000-m \\
\text { fixed } \\
\text { running }\end{array}$ & $\begin{array}{l}\text { uphill } \\
\text { interval } \\
\text { training }\end{array}$ & & & \\
\hline & Lower & $\begin{array}{l}50-\text { min } \\
\text { fixed } \\
\text { running }\end{array}$ & $\begin{array}{l}60-\mathrm{min} \\
\text { fixed } \\
\text { running }\end{array}$ & & $\begin{array}{l}8000-m \\
\text { fixed } \\
\text { running }\end{array}$ & $\begin{array}{l}\text { uphill } \\
\text { interval } \\
\text { training }\end{array}$ & & & \\
\hline $\begin{array}{l}\text { Running } \\
\text { distance }\end{array}$ & Higher & $\begin{array}{l}9700 \\
(9250- \\
10150) *\end{array}$ & $\begin{array}{l}12790 \\
(12300- \\
13450)\end{array}$ & 0.002 & $\begin{array}{l}8000 \\
(8000- \\
8000)\end{array}$ & $\begin{array}{l}12000 \\
(9800- \\
14000) \star \star\end{array}$ & 0.002 & 0.002 & 0.686 \\
\hline$(\mathrm{m})$ & Lower & $\begin{array}{l}11585 \\
(10700- \\
12000)\end{array}$ & $\begin{array}{l}13145 \\
(12445- \\
14000)\end{array}$ & 0.004 & $\begin{array}{l}8000 \\
(8000- \\
8000)\end{array}$ & $\begin{array}{l}4700 \\
(4200- \\
5250)\end{array}$ & 0.002 & 0.002 & 0.002 \\
\hline $\begin{array}{l}\text { Running } \\
\text { velocity }\end{array}$ & Higher & $\begin{array}{l}242.5 \\
(224.8- \\
247.7)^{\star}\end{array}$ & $\begin{array}{l}252.0 \\
(246.0- \\
263.0)^{\star}\end{array}$ & 0.002 & $\begin{array}{l}235.3 \\
(228.6- \\
238.9)\end{array}$ & $\begin{array}{l}178.0 \\
(153.9- \\
215.4)\end{array}$ & 0.002 & 0.272 & 0.003 \\
\hline$(\mathrm{m} / \mathrm{min})$ & Lower & $\begin{array}{l}224.2 \\
(205.0- \\
236.8)\end{array}$ & $\begin{array}{l}219.1 \\
(207.5- \\
233.3)\end{array}$ & 0.477 & $\begin{array}{l}235.3 \\
(228.6- \\
236.5)\end{array}$ & $\begin{array}{l}168.0 \\
(125.0- \\
213.8)\end{array}$ & 0.003 & 0.308 & 0.023 \\
\hline \multirow[t]{2}{*}{$\begin{array}{l}\text { Borg Scale } \\
\text { score }\end{array}$} & Higher & $\begin{array}{l}13.0 \\
(12.0- \\
15.0)^{\star}\end{array}$ & $\begin{array}{l}15.0 \\
(13.0- \\
15.5)\end{array}$ & 0.010 & $\begin{array}{l}13.0 \\
(12.0- \\
15.0)\end{array}$ & $\begin{array}{l}16.0 \\
(14.0- \\
17.5)^{\star \star}\end{array}$ & 0.004 & 0.864 & 0.072 \\
\hline & Lower & $\begin{array}{l}14.0 \\
(13.0- \\
15.5)\end{array}$ & $\begin{array}{l}13.5 \\
(12.0- \\
15.0)\end{array}$ & 0.119 & $\begin{array}{l}13.0 \\
(12.0- \\
15.0)\end{array}$ & $\begin{array}{l}13.0 \\
(12.5- \\
15.0)\end{array}$ & 0.524 & 0.203 & 0.565 \\
\hline $\begin{array}{l}\text { Maximum } \\
\text { pulse rate }\end{array}$ & Higher & $\begin{array}{l}175 \\
(159- \\
189)\end{array}$ & $\begin{array}{l}182 \\
(159- \\
201)\end{array}$ & 0.182 & $\begin{array}{l}170 \\
(152- \\
184)^{\star}\end{array}$ & $\begin{array}{l}179 \\
(165- \\
192)^{\star}\end{array}$ & 0.167 & 0.937 & 0.666 \\
\hline (beat/min) & Lower & $\begin{array}{l}168 \\
(153- \\
198)\end{array}$ & $\begin{array}{l}168 \\
(158- \\
181)\end{array}$ & 0.937 & $\begin{array}{l}196 \\
(164- \\
210)\end{array}$ & $\begin{array}{l}163 \\
(154- \\
187)\end{array}$ & 0.050 & 0.034 & 0.760 \\
\hline
\end{tabular}

Data are expressed as median (25th-75th percentile).

${ }^{*} p<0.05$ and ${ }^{* \star} p<0.01$ comparing variables between the higher- and lower-altitude camps using the Wilcoxon signed-rank test.

$p_{\text {day } 1}$ morning exercise vs. afternoon exercise on day 1 using the Wilcoxon signed-rank test.

$p_{\text {day2 }}$ morning exercise vs. afternoon exercise on day 2 using the Wilcoxon signed-rank test.

$p_{\mathrm{m}}$ day 1 vs. day 2 in morning exercise using the Wilcoxon signed-rank test.

$p_{\mathrm{a}}$ day 1 vs. day 2 in afternoon exercise using the Wilcoxon signed-rank test. 
Changes in the salivary cortisol concentrations in response to exercise within the circadian rhythms on 2 consecutive days during the higher- or lower-altitude camps

Figure 2 presents the changes in the salivary cortisol concentrations in response to exercise during the circadian rhythms on last 2 days of both camps. The salivary cortisol concentrations peaked after waking and promptly decreased in the last 2 days of both camps. Within these circadian rhythms, the salivary cortisol concentrations significantly decreased after the morning exercise in the last 2 days of both camps but significantly increased after the afternoon exercise in the last 2 days of only the higher-altitude camp. These concentrations reached their lowest levels before dinner in the last 2 days of both camps. Table 3 presents that the differences in the resting pulse rate and salivary cortisol concentrations between the higher- and lower-altitude camps. The resting pulse rate before dinner was significantly higher on day 2 of the higher-altitude camp than on day 2 of the loweraltitude camp $(p=0.021)$. The salivary cortisol concentrations upon waking up were significantly lower on both days of the higher-altitude camp than on day 2 of the lower-altitude camp (H-day 1 vs. L-day 2, $p=0.038 ; \mathrm{H}$-day 2 vs. L-day $2, p=0.025)$. The concentrations before dinner were also significantly higher on both days of the higher-altitude camp than those on both days of the lower-altitude camp (H-day 1 vs. L-day $1, p=0.026 ; \mathrm{H}$-day 1 vs. L-day 2, $p=0.005 ; \mathrm{H}$-day 2 vs. L-day 1, $p=0.012 ; \mathrm{H}$-day 2 vs. L-day 2, $p=0.003$ ).

Table 3

Comparison of the variables between the higher- and lower-altitude camps in runners.

\begin{tabular}{|c|c|c|c|c|}
\hline & \multicolumn{2}{|c|}{ Higher-altitude camp } & \multicolumn{2}{|c|}{ Lower-altitude camp } \\
\hline & day 1 & day 2 & day 1 & day 2 \\
\hline $\begin{array}{l}\text { Resting pulse rate at awakening } \\
\text { (beat/min) }\end{array}$ & $50(46-55)$ & $49(44-52)$ & $48(44-52)$ & $50(42-57)$ \\
\hline $\begin{array}{l}\text { Resting pulse rate before dinner } \\
\text { (beat/min) }\end{array}$ & $65(57-70)$ & $65(57-71)^{\dagger}$ & $56(52-68)$ & $54(48-63)$ \\
\hline $\begin{array}{l}\text { Salivary Cortisol at awakening } \\
(\mathrm{mg} / \mathrm{dL})\end{array}$ & $\begin{array}{l}0.41(0.37- \\
0.45)^{+}\end{array}$ & $\begin{array}{l}0.36(0.31- \\
0.42)^{+}\end{array}$ & $\begin{array}{l}0.40(0.33- \\
0.43)\end{array}$ & $\begin{array}{l}0.43(0.39- \\
0.50)\end{array}$ \\
\hline Salivary Cortisol at peak(mg/dL) & $\begin{array}{l}0.57(0.44- \\
0.61)\end{array}$ & $\begin{array}{l}0.51(0.45- \\
0.61)\end{array}$ & $\begin{array}{l}0.49(0.43- \\
0.59)\end{array}$ & $\begin{array}{l}0.55(0.42- \\
0.64)\end{array}$ \\
\hline $\begin{array}{l}\text { Salivary Cortisol before dinner } \\
\text { (mg/dL) }\end{array}$ & $\begin{array}{l}0.15(0.09- \\
0.18)^{\star++}\end{array}$ & $\begin{array}{l}0.11(0.09- \\
0.25)^{\star++}\end{array}$ & $\begin{array}{l}0.08(0.06- \\
0.11)\end{array}$ & $\begin{array}{l}0.05(0.05- \\
0.07)\end{array}$ \\
\hline \multicolumn{5}{|c|}{ Data are expressed as median (25th-75th percentile). } \\
\hline \multicolumn{5}{|c|}{$\begin{array}{l}* p<0.05 \text { and }{ }^{* *} p<0.01 \text { comparing variables with day } 1 \text { in the lower-altitude camp using the Wilcoxon } \\
\text { signed-rank test. }\end{array}$} \\
\hline \multicolumn{5}{|c|}{$\begin{array}{l}{ }^{\dagger} p<0.05 \text { and }{ }^{\dagger \dagger} p<0.01 \text { comparing variables with day } 2 \text { in the lower-altitude camp using the Wilcoxon } \\
\text { signed-rank test. }\end{array}$} \\
\hline
\end{tabular}

Rate of change in the salivary cortisol concentrations resulting from exercise in the higher-and lower-altitude camps

Figure 3 presents the comparison of the rate of change in the salivary cortisol concentrations after each exercise in both camps. The rates of change in salivary cortisol concentrations were significantly lower during the 
morning exercise than during the afternoon exercise on both days of each camp (H-day $1, p=0.002 ; \mathrm{H}$-day $2, p=$ 0.002; L-day 1, $p=0.005$; L-day 2, $p=0.008$; Fig. 3A, 3B). After the morning exercise, the rate of change in the salivary cortisol concentration was significantly higher on day 2 of the higher-altitude camp than on day 2 of the lower-altitude camp ( $p=0.028$; Fig. 3C). After the afternoon exercise, the rate of change in the salivary cortisol concentration was significantly higher on both days of the higher-altitude camp than on both days of the loweraltitude camp (H-day 1 vs. L-day 1, $p=0.012 ; \mathrm{H}$-day 2 vs. L-day 2, $p=0.003 ;$ Fig. 3D). The rate of change in the salivary cortisol concentration after the afternoon exercise was also significantly higher on day 2 than on day 1 of the higher-altitude camp ( $p=0.028$; Fig. 3D).

\section{Discussion}

In this study, we determined whether the stress responses of runners in training camps at different altitudes could be evaluated via sequential saliva collection and automated salivary cortisol measurement. These methods were able to detect the basal levels and exercise-induced changes in the salivary cortisol within the runners' circadian rhythms in each altitude camp. The basal salivary cortisol concentrations before dinner were significantly higher in the higher-altitude camp than in lower-altitude camp. The rate of change in the salivary cortisol concentration during the afternoon exercise on days 1 and 2 and the indicators of exercise intensity were significantly higher in the higher-altitude camp than in the lower-altitude camp. Moreover, the rate of change in the salivary cortisol concentration during the morning exercise on day 2 was significantly higher in the higher-altitude camp than in lower-altitude camp; no differences were observed in the exercise programs and intensities, such as the running distances, velocities, and Borg scale scores.

There have been contradictory reports with regard to the effects of high-altitude training on cortisol secretions. In male elite climbers, the resting serum cortisol and plasma ACTH levels taken at 07:00-07:30 did not change at $5200 \mathrm{~m}$ extreme altitude camp compared with those at sea level [7]. In male and female elite skiers, no significant differences were observed in resting salivary cortisol concentrations taken at 07:00-08:00 between the control group training and living at an altitude of $1200 \mathrm{~m}$ and another group training at $1200 \mathrm{~m}$ but living at a simulated altitudes of $2500 \mathrm{~m}, 3000 \mathrm{~m}$ and $3500 \mathrm{~m}$ for 6 days in hypoxic rooms [8]. The resting salivary cortisol concentrations in both groups remained unchanged throughout this study. Contrarily, a previous study revealed that the basal concentrations of serum cortisol in the morning after 3-4 days at $4350 \mathrm{~m}$ were elevated compared with those at sea levels in healthy men, but this was not statistically significant [9]. In the present study, a significant difference was observed in the basal salivary cortisol concentrations before dinner with an altitude difference of about $300 \mathrm{~m}$ between the two camps, even at altitudes of 1300-1800 m. These differences may be due to the fact that we compared the lowest cortisol levels in the evening in accordance to the circadian rhythms, whereas the previous studies compared the concentrations in the morning [7-9]. Another reason may be that the athletes were acclimatized to the high altitude when transitioning from the first camp to the second camp at lower altitude. Overtraining syndrome presents with a reduced cortisol response to exercise and changes in the circadian rhythms, including low levels of resting cortisol and peak loss after awakening [19, 20]. In the present study, the runners' salivary cortisol concentrations were low in the evening, but peaked after awakening and responded to increase after high-intensity exercise. The low levels of salivary cortisol in the evening indicate that the runners did not suffer from overtraining syndrome but were rather able to adapt to the high altitude. Although further analysis under higher-altitude conditions is required, it may be more useful to 
evaluate the cortisol levels in the evening rather than in the morning using serum or saliva to determine if the athlete have acclimatized to the high-altitude environment.

With regard to the acute response of exercise, the increase in cortisol level after interval training at 09:00 exhibited an insignificant trend toward higher values at an altitude of $1800 \mathrm{~m}$ when compared with that at near sea levels in highly trained endurance athletes [10]. The serum cortisol levels significantly increased after resistance training at $70 \%$ of the maximum strength under $13 \%$ hypoxic conditions from 08:00 to 11:30 but not under normoxic conditions in healthy male subjects [11]. Conversely, the serum cortisol levels did not change after resistance training at $50 \%$ of the maximum strength under hypoxic and normoxic conditions [12]. In the present study, the rates of change in the salivary cortisol concentration after the morning exercise were significantly lower than those after the afternoon exercise on all days of each altitude camp due to the influence of the circadian rhythm, which is validated by previous reports $[13,16]$. Contrarily, the comparison of the rates of change in cortisol concentration during exercise within the circadian rhythm at the same time on different days, whether in the morning or in the afternoon, is effective in evaluating the stress responses, as previously described [16]. In the present study, we were able to detect the difference in the rates of change in the salivary cortisol concentration during exercise with the same program at different altitudes, even in the morning. Moreover, we could detect the increase in stress due to the differences in altitude and exercise intensity, more clearly in the afternoon, by assessing the rate of change in salivary cortisol concentrations. This result validates the previous studies, wherein the serum cortisol concentrations were acutely elevated by high-intensity exercise with higher $\mathrm{VO}_{2 \text { max }}$ or $\mathrm{VO}_{2 \text { peak }}$ [4-6]. However, we did not measure the $\mathrm{SpO}_{2}$ or $\mathrm{VO}_{2 \text { max }}$ as the oxygen tolerability of runners for different exercise intensities. Future studies should evaluate the relationships between the changes in salivary cortisol concentrations and these oxygen tolerability markers in response to endurance exercise at different altitudes.

This study has several limitations. First, the sample size was relatively small. We focused on enrolling welltrained female runners with standardized meal and sleep times during the two consecutive camps. Second, the sequential saliva collections and measurements of salivary cortisol concentration were not performed at sea level. The temperatures were around $20^{\circ} \mathrm{C}$ during both altitude camps, but the temperature during the same period was as high as $30^{\circ} \mathrm{C}-40^{\circ} \mathrm{C}$ at near sea level where the runners lived and trained. The salivary cortisol levels in a maximal progressive test on a cycle ergometer were reported to be significantly higher under the hot conditions $\left(40^{\circ} \mathrm{C}\right)$ than under normal conditions $\left(22^{\circ} \mathrm{C}\right)$ in a study involving nine young healthy men [21].

Therefore, it was impossible in our study to collect saliva above sea level because it is affected the stress due to high temperatures more than the difference in altitude. Future study should involve hypoxic rooms, wherein the environmental conditions including temperature are standardized. In addition, more runners should be enrolled, specifically males.

\section{Conclusions}

Even at the altitude camp of about $1500 \mathrm{~m}$, measurement of the salivary cortisol levels within the circadian rhythm led to the detection of the stress response due to the difference in altitude of about $300 \mathrm{~m}$. The salivary cortisol concentration can also assess the altitude acclimatization via transition from higher-altitude to loweraltitude camp. The combination of sequential saliva collection and automated cortisol measurements may be 
useful for assessing adaptation disorders and excessive exercise stress and also help develop adequate highaltitude training programs for athletes.

\section{Abbreviations}

ECLIA: electrochemiluminescence immunoassay, $\mathrm{VO}_{2}$ max: maximal oxygen consumption, $\mathrm{VO}_{2}$ peak: peak oxygen uptake

\section{Declarations}

\section{Ethics approval and consent to participate}

Written informed consent was obtained from all participants. This study was approved by the ethics committee of Gunma University Graduate School of Medicine (Approval number HS2018-140).

\section{Consent for publication}

Not applicable.

\section{Availability of data and material}

Please contact the corresponding author for reasonable data requests.

\section{Competing interests}

The authors declare that they have no competing interests.

\section{Funding}

This work was supported by the Ministry of Education, Culture, Sports, Science, and Technology of Japan [grant numbers 18K07406].

\section{Authors' contributions}

KT participated in the collection and analysis of data and manuscript writing, reviewing and editing. $K U, L M, A N$, $\mathrm{RH}, \mathrm{RS}, \mathrm{NS}, \mathrm{MM}, \mathrm{AY}, \mathrm{NK}$, and TK participated in data collection and analysis. MM participated in conception of the study, supervision, and manuscript editing. All authors read and approved the final manuscript.

\section{Acknowledgement}

We are grateful to Kenichi Morikawa, Mayumi Nishiyama, and Tomoyuki Aoki for providing technical assistance and helpful discussions.

\section{Authors' information}

Not applicable

\section{References}


1. Wang GL, Jiang BH, Rue EA, Semenza GL. Hypoxia-inducible factor 1 is a basic-helix-loop-helix-PAS heterodimer regulated by cellular $\mathrm{O}_{2}$ tension. Proc Natl Acad Sci U S A. 1995;92(12):5510-4.

2. Flaherty G, O'Connor R, Johnston N. Altitude training for elite endurance athletes: A review for the travel medicine practitioner. Travel Med Infect Dis. 2016;14(3):200-11.

3. Hackney AC. Stress and the neuroendocrine system: the role of exercise as a stressor and modifier of stress. Expert Rev Endocrinol Metab. 2006;1(6):783-92.

4. Davies CT, Few JD. Effects of exercise on adrenocortical function. J Appl Physiol. 1973;35(6):887-91.

5. Hill EE, Zack E, Battaglini C, Viru M, Viru A, Hackney AC. Exercise and circulating cortisol levels: the intensity threshold effect. J Endocrinol Invest. 2008;31(7):587-91.

6. Sato K, lemitsu M, Katayama K, Ishida K, Kanao Y, Saito M. Responses of sex steroid hormones to different intensities of exercise in endurance athletes. Exp Physiol. 2016;101(1):168-75.

7. Benso A, Broglio F, Aimaretti G, Lucatello B, Lanfranco F, Ghigo E, et al. Endocrine and metabolic responses to extreme altitude and physical exercise in climbers. Eur J Endocrinol. 2007;157(6):733-40.

8. Tiollier E, Schmitt L, Burnat P, Fouillot JP, Robach P, Filaire E, et al. Living high-training low altitude training: effects on mucosal immunity. Eur J Appl Physiol. 2005;94(3):298-304.

9. Richalet JP, Leteournel M, Souberbielle JC. Effects of high-altitude hypoxia on the hormonal response to hypothalamic factors. Am J Physiol Regul Integr Comp Physiol. 2010;299(6):R1685-92.

10. Niess AM, Fehrenbach E, Strobel G, Roecker K, Schneider EM, Buergler J, et al. Evaluation of stress responses to interval training at low and moderate altitudes. Med Sci Sports Exerc. 2003;35(2):263-9.

11. Kon M, Ikeda T, Homma T, Akimoto T, Suzuki Y, Kawahara T. Effects of Acute Hypoxia on Metabolic and Hormonal Responses to Resistance Exercise. Med Sci Sports Exerc. 2010;42(7):1279-85.

12. Kon M, Ikeda T, Homma T, Suzuki Y. Effects of low-intensity resistance exercise under acute systemic hypoxia on hormonal responses. J Strength Cond Res. 2012;26(3):611-7.

13. Chtourou H, Hammouda O, Aloui A, Chaabouni K, Makni-Ayedi F, Wahl M, et al. The effect of time of day on hormonal responses to resistance exercise. Biol Rhythm Res. 2014;45(2):247-56.

14. Peters JR, Walker RF, Riad-Fahmy D, Hall R. Salivary cortisol assays for assessing pituitary-adrenal reserve. Clin Endocrinol. 1982;17(6):583-92.

15. Hofman LF. Human saliva as a diagnostic specimen. J Nutr. 2001;131(5):1621S-1625S.

16. Ushiki K, Tsunekawa K, Shoho Y, Martha L, Ishigaki H, Matsumoto R, et al. Assessment of exercise-induced stress by automated measurement of salivary cortisol concentrations within the circadian rhythm in Japanese female long-distance runners. Sports Med Open. 2020;6(1):38.

17. Borg GAV. Psychophysical bases of perceived exertion. Med Sci Sports Exerc. 1982;14:377-81.

18. Gagnon N, Frechette I, Mallet PL, Dube J, Houde G, Fink GD. Establishment of reference intervals for the salivary cortisol circadian cycle, by electrochemiluminescence (ECLIA), in healthy adults. Clin Biochem. 2018;54:56-60.

19. Urhausen A, Kindermann W. Diagnosis of overtraining: what tools do we have? Sports Med. 2002;32(2):95102.

20. Cadegiani FA, Kater CE. Novel causes and consequences of overtraining syndrome: the EROS-DISRUPTORS study. BMC Sports Sci Med Rehabil. 2019;11(1):21. 
21. Silva RPM, Barros CLM, Mendes TT, Garcia ES, Valenti VE, de Abreu LC, et al. The influence of a hot environment on physiological stress responses in exercise until exhaustion. PLoS One. 2019;14(2):e0209510.

Figures

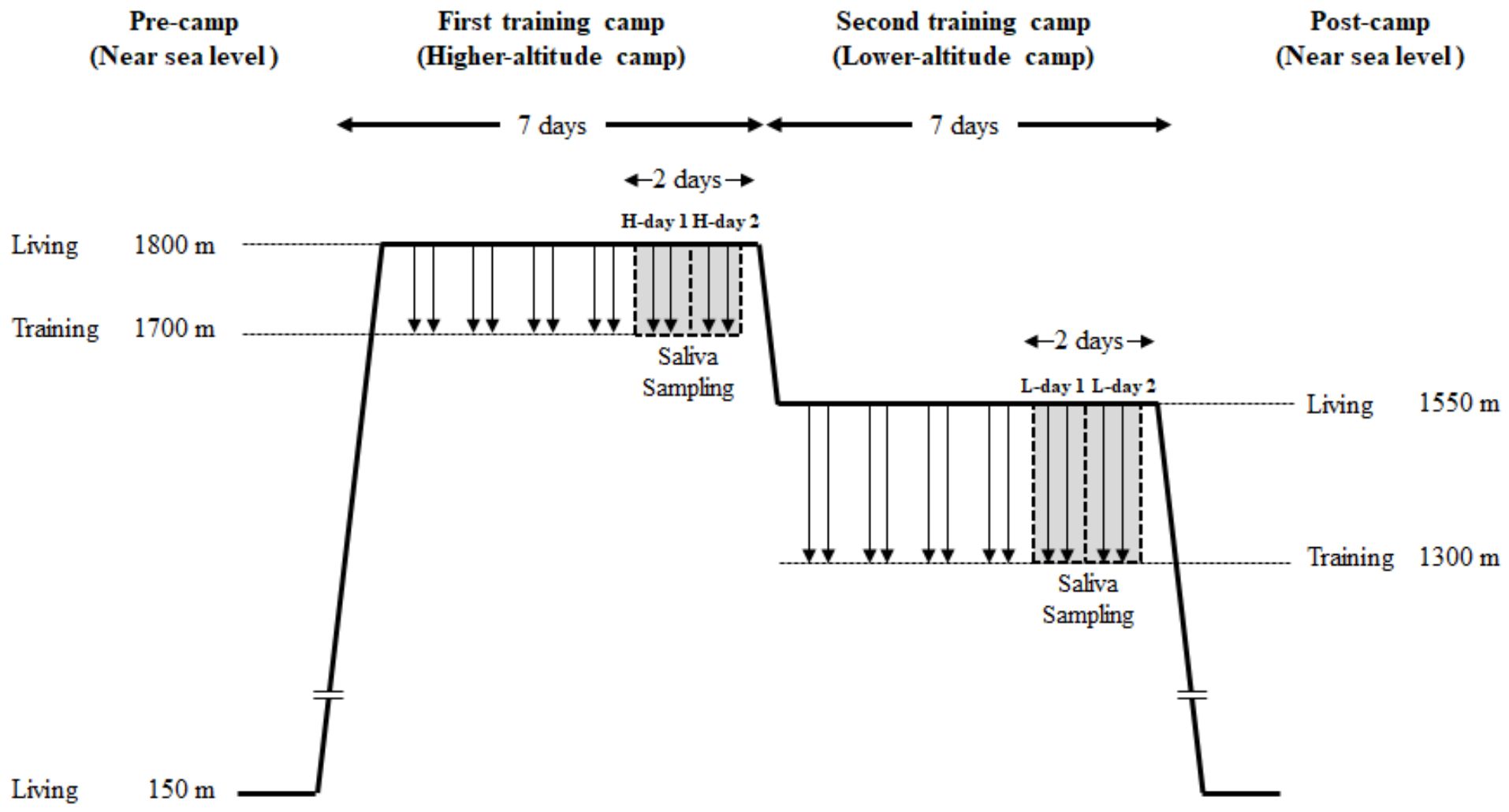

\section{Figure 1}

The study design of the first and second training camps of 12 female long-distance runners. The downwards arrows denote the exercise training in both camps. 
A

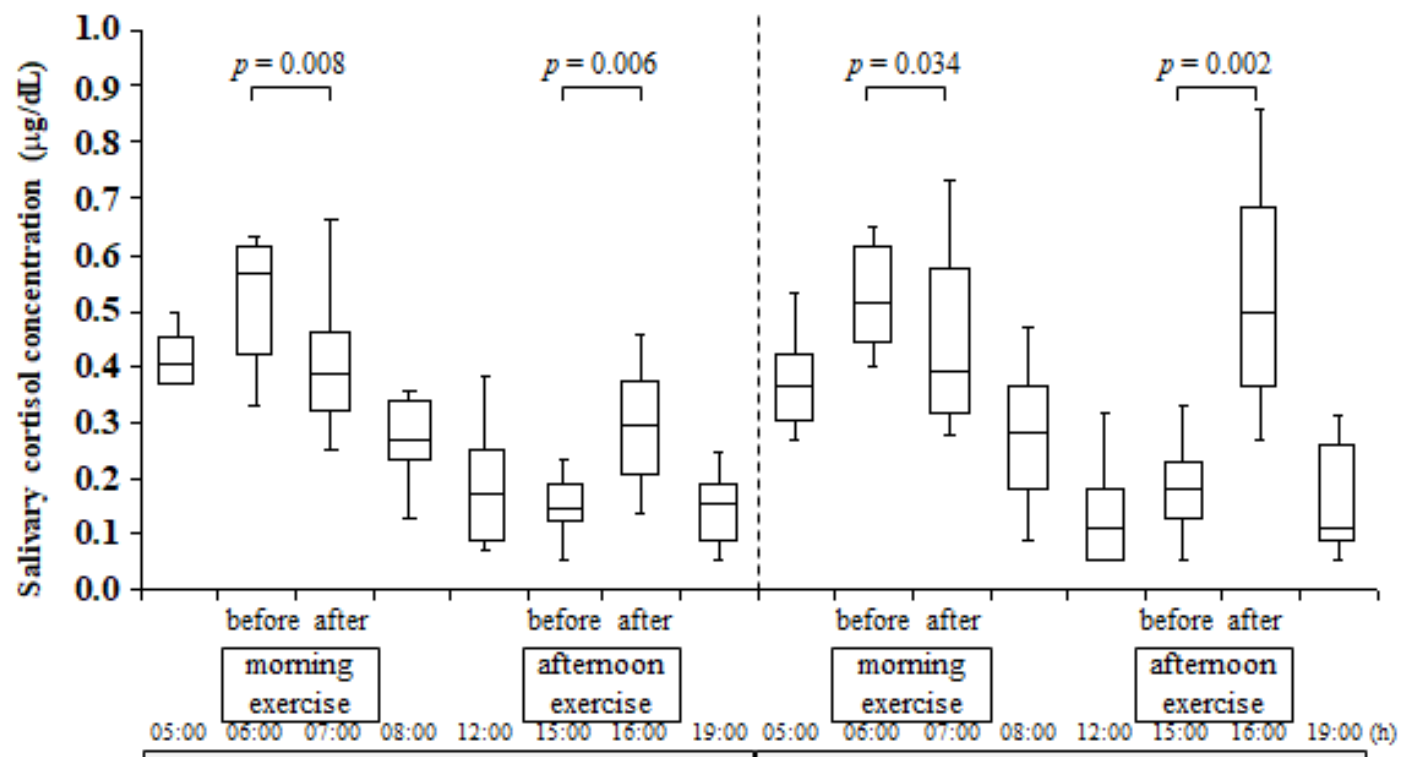

H-day 1

H-day 2

B

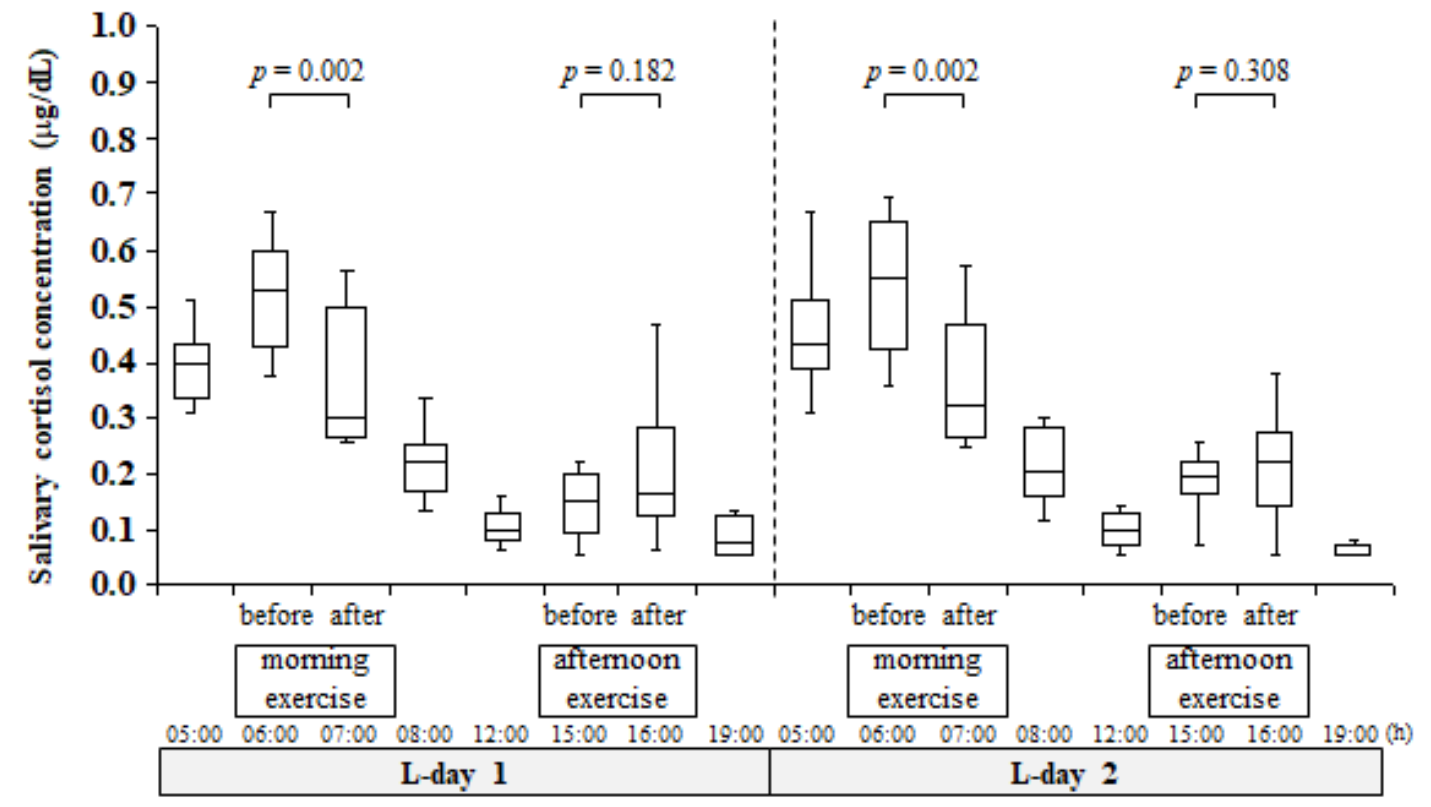

Figure 2

Changes in salivary cortisol concentrations in response to each exercise within the circadian rhythm on 2 consecutive days during the higher-altitude camp (A) and lower-altitude camp (B). The significant differences between two time points of each exercise for runners were analyzed using the Wilcoxon signed-rank test. 
A

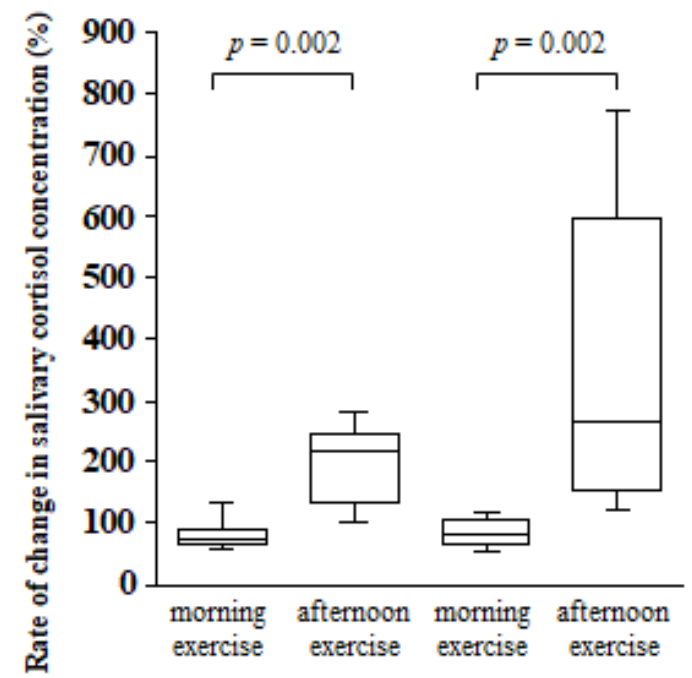

H-day 1

\section{C}

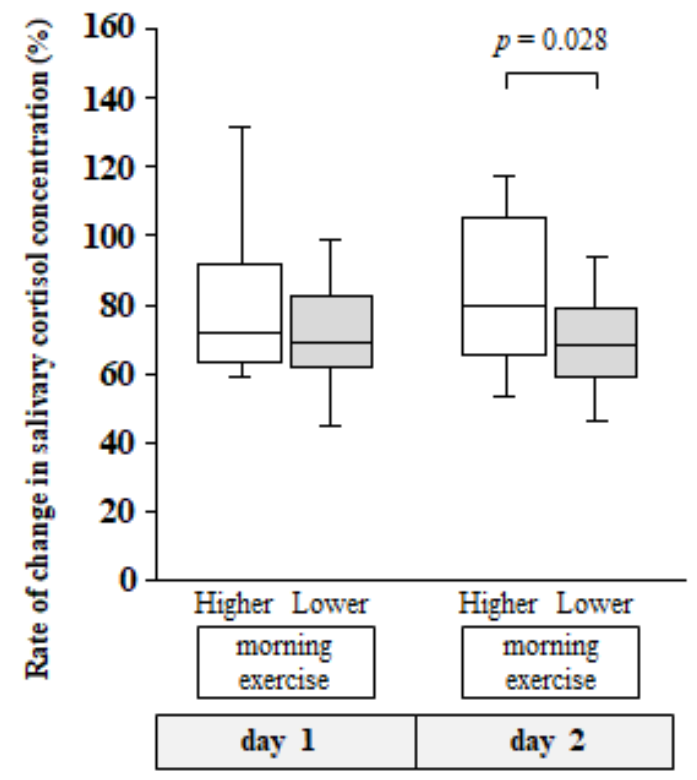

B

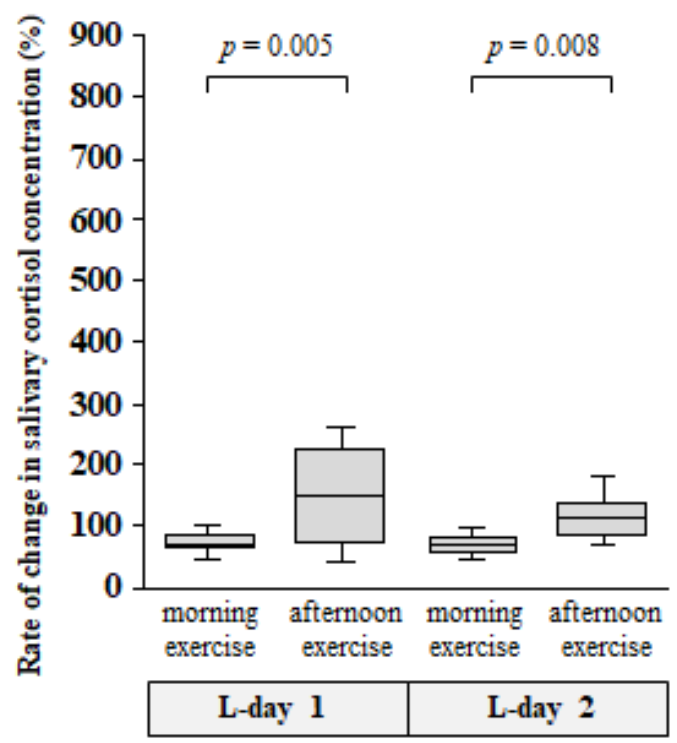

D

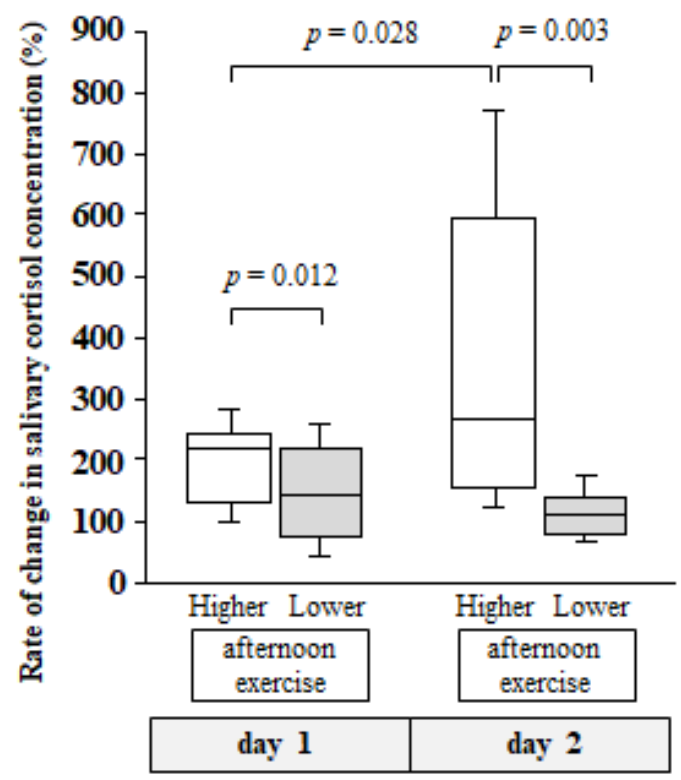

\section{Figure 3}

Comparison of the rate of change in the salivary cortisol concentration resulting from exercise between the morning and afternoon time points on days 1 and 2 in the higher-altitude camp (A), lower-altitude camp (B), between the morning time points on days 1 and 2 in the higher- and lower-altitude camps (C), and between the afternoon time points on days 1 and 2 in the higher- and lower-altitude camps (D). The white box plots denote the rates of change in the cortisol concentration in the higher-altitude camp, whereas the gray box plots represent those in the lower-altitude camp. The significant differences between two time points of exercise for runners were analyzed using the Wilcoxon signed-rank test. 